\title{
How role-taking in a group-work setting affects the relationship between the amount of collaboration and germane cognitive load
}

\author{
Jamie Costley ${ }^{*}$ (1)
}

\section{*Correspondence:}

jcostley@hse.ru

National Research University

Higher School of Economics,

Institute of Education,

Myasnitskaya Ulitsa, 20,

Moscow 101000, Russia

\begin{abstract}
This research investigates how learning groups affect student learning from two perspectives: first, the amount of group work students do, and second, the role that they take within the group. It is not clear from the current research how a student's role in collaborative learning affects his/her development of critical thinking and the construction of knowledge. The present study looks into whether the positive relationships found between collaboration and germane cognitive load are affected by a learner's role within the group. Using cognitive load theory, this study analyzed survey responses from a group of university students $(n=1399)$ who engaged in collaborative study groups when taking online classes in South Korea. While it was found that the amount of collaboration a student engaged in positively affected levels of germane load and that their level of contribution negatively moderated that relationship. In other words, while more group work is beneficial, students who contribute less to the group have greater gains from higher levels of collaboration than students who take a more active role.
\end{abstract}

Keywords: Cognitive load, Collaboration, Germane cognitive load, Group work, Group role, Korea

\section{Introduction}

Developing an understanding of how an individual's ability to contribute to online group work and how those groups collaborate and share information is an important aspect of research into online learning at the tertiary level (Herrmann, 2013). Group work and study groups are ubiquitous in higher education and have been shown to benefit students in terms of their performance and learning (Chen \& Yang, 2019). When dealing with the complex and sophisticated problems facing many learners, the shared and complementary skills and knowledge of a group may be beneficial in processing information (Swanson et al., 2019). To help understand how and why group work might benefit learners, we should consider the cognitive underpinnings of how collaboration interacts with learning (DeChurch \& Mesmer-Magnus, 2010). From this perspective, group work is effective for several reasons. The first is how it might overcome limitations learners have in processing certain pieces of information (Zhang et al., 2016). The second is the

(c) The Author(s), 2021. Open Access This article is licensed under a Creative Commons Attribution 4.0 International License, which permits use, sharing, adaptation, distribution and reproduction in any medium or format, as long as you give appropriate credit to the original author(s) and the source, provide a link to the Creative Commons licence, and indicate if changes were made. The images or other third party material in this article are included in the article's Creative Commons licence, unless indicated otherwise in a credit line to the material. If material is not included in the article's Creative Commons licence and your intended use is not permitted by statutory regulation or exceeds the permitted use, you will need to obtain permission directly from the copyright holder. To view a copy of this licence, visit http:// creativecommons.org/licenses/by/4.0/. 
potential for increasing individual performance and metacognitive abilities by going through the processes of collaboration (Zheng et al., 2019). Finally, increasing student's feelings of emotional support while learning may help overcome some issues of information processing (Hernández-Sellés et al., 2019).

One way of understanding these cognitive processes occurring during collaborative learning is through cognitive load theory. There are three elements that make up cognitive load theory: germane load (effort to store information), extraneous load (processing of unnecessary information), and intrinsic load (content complexity). All three elements are connected to how learners process information from their long-term memories to their short-term memories and subsequently retain the information (Klepsch \& Seufert, 2020). Germane cognitive load is the mental effort that is devoted to retaining information and generating schema of the knowledge to be learned. This system focuses cognitive resources on the processes that will benefit learning (Kirschner et al., 2011). For this reason, germane cognitive load is a useful way to understand how different aspects of group work interact with an individual's cognitive processing during group work. There is a well subscribed body of research using cognitive load theory to understand collaboration in online learning environments (Kirschner et al., 2018). However, there is a gap in the research regarding the degree to which the amount of interaction and roles learners take in collaboration will cognitively benefit them. The debate is focused on two differing claims, with the first being that highly motivated students who also contribute substantially to group work are likely to gain the most from learner-to-learner interaction (Homer et al., 2008). This perspective argues that learners who have high levels of motivation are likely to participate more and make greater contributions to planning and leadership in groups than those with lower levels of motivation, which may lead to greater gains in learning (Rienties et al., 2009). The second, opposing claim is that group work offers a type of scaffolding for learners who may lack motivation or contribute relatively little to the group and that they have the most to gain when engaged in group work (Costley \& Lange, 2018).

To understand collaboration from two different points of view, two constructs related to group work that were used: group role or contribution, which measured the degree to which each member of the group perceived they contributed to the work that was done; and the amount of group work, which measured the different types of group work students did and how often they engaged in group work. The types of group activities the students engaged in included talking about how they felt about the class, discussing the contents and general information about the class (for example, assignment due dates, checking of the answers to essay questions). The distinction between these two constructs is that the amount of group work refers to the amount and types of group work that the learners engaged in as a part of their class. For example, groups that met more often and engaged in more varied group work (e.g., sharing notes, opinions, and support) would score more highly on this metric. The second construct role or contribution in group work refers to how participants behaved once they were in their groups. This categorized group members into those who contributed a high, moderate, or low amount when they met together. To examine the impact of group work on learning, the present study draws upon literature related to cognitive load theory to gauge and to compare the effects of two different factors in student-to-student interaction: learner role and amount of group 
work. This research intends to explore the current lack of clarity over the relationship between how students collaborate and how they process information in the form of germane cognitive load. In particular, this research asks the following questions:

1. Is there an association between the amount of group work learners engage in and their levels of germane cognitive load?

2. Does that association vary according to the group members' roles as high, moderate, or low contributors?

In order to understand the interactions between the group and learning, this study will empirically test a conceptual framework that centers on the moderating effects of the following three factors and the relationships among them: group member roles, amount of group, and germane cognitive load. The students who participated in this study were engaged in a wide variety of types of group work. This study seeks to give an overview of group work in general and its effects on cognitive load. Therefore, the current study examines the following hypotheses:

H1: There is a positive relationship between the amount of group work and germane load.

$\mathrm{H} 2$ : There is a positive relationship between the group work role and germane load.

H3: The role in group work moderates the relationship between the amount of group work and germane load.

\section{Literature review}

\section{The amount of group work and germane cognitive load}

The self-explanation principle claims that when students teach themselves something, it may enhance their own levels of germane load for that particular unit of information (Hefter \& Berthold, 2020). The corollary to this is that students who teach information to others will also tend to have a more thorough and deeper grasp of that subject (Duran, 2017). Furthermore, as students engage in more of these types of interactions, the processes that are involved in the development and building of complex and authentic learning are further developed (Andriessen et al., 2003). This benefits learning in online contexts, with learners who work together showing higher levels of cognition (Akyol \& Garrison, 2008). Tsay and Brady (2012) have shown that students who are engaged in group work learn more, and the more the students interact with one another, the greater the learning.

While the benefits to learning that are gained through group work are clear and well established, not all contexts in which students interact with one another benefit students' levels of learning (Thom, 2020). A fundamental issue with any task or learning activity that a group may need to complete is the cognitive transaction cost that is born by the members of the group when participating in the student-to-student distribution of information, or in the completion of any given group task (Kirschner et al., 2009). The groups' increase in cognitive processing through the division of assignments across differing members may be counteracted or neutralized by the transaction cost of interaction. From this perspective, we need to consider whether all increases in collaboration will lead to improvements in learning. However, the majority of research into 
collaborative learning suggest that the more types of group work students engage in, and the more often they engage in that group work, the better their levels of engagement with the contents and subsequent learning of the materials. Collaborative learning does have some theoretical basis for affecting a learner's levels of cognitive load, with some evidence showing improvements in levels of germane load when learners collaborate, as well as a mitigating effect of collaboration on the more challenging elements of some learning environments (Kirschner et al., 2011).

\section{Role-taking in group settings and germane cognitive load}

Teams that are efficient and effective link compatible elements of each individual's cognitive understanding of their tasks (Cooke et al., 2007). In group-based tasks, a group of individuals must coalesce and contribute together towards the objective of what is to be learned to augment in-class learning (Johnson et al., 2014). In this context learners will take on different roles and contribute to different levels. Learners with high levels of motivation are more likely to contribute to group work through planning, sharing of information, and cognitively-focused discourse in group learning contexts (Rienties et al., 2009). When learners interact, they must subsume their own goals to the goals of the group to some degree (Wosnitza \& Volet, 2009). Highly motivated students who are likely to contribute substantially may face greater challenges in a group as they bring a stronger sense of their own goals, which may conflict with the group goals (Järvelä et al., 2010). Regardless, there is some suggestion that those who contribute more in collaboration learning environments will have greater cognitive benefits (Kirschner et al., 2018).

\section{Role-takings affect on the relationship between amount of group work and germane cognitive load}

The question of who within a group benefits the most from higher levels of interaction is open, and an understanding of how different types of learners may benefit is an important part of research into learner-to-learner interactions. More motivated and active students tend to push in a positive direction only when they realize they can succeed only if the whole group does, which tends to lead them to make greater contributions and share more information that benefits all learners (Johnson \& Johnson, 2003). This allows all group members to support each other, and students who may have contributed less to knowledge sharing receive all of the benefits of the group's knowledge and production (Pee et al., 2010). Therefore, students who are less active and who may not have contributed greatly to the group directly are able to be scaffolded by the students who have made greater contributions through the adoption of the goals of the group as a whole (Johnson \& Johnson, 2003). This suggests that role-taking may moderate the relationship between the amount of group work and germane load, as students who have a lesser role in group work benefit more from higher amounts of collaboration.

\section{Methods}

\section{Research procedures and data collection}

A quantitative approach was employed, using surveys to help understand the research questions that were a part of the present study. The survey used in this research was the fourth in a series of large surveys into the OCU. The items were written first in English 
and then translated into Korean, which is the native language of students taking OCU classes. From there, an expert in online learning, in general, and the OCU as a learning platform, specifically, checked the survey's translated items to verify that they were accurate reliable translations of the English items. The survey in a Google Sheets form, was then sent to the main ethics and administrative offices of the OCU for verification that the items and survey were appropriate for distribution to the students of the OCU. The OCU administration then posted a link to the survey, inviting students to participate in the research project.

\section{Respondent profile}

The intent of this study was to investigate the direct and moderating effects of perceptions of the types of study group activities on perceived germane cognitive load in online learning situations. In order to do so, the study draws on research from the fields of educational technology and cognitive psychology. The present research examined learners taking classes at the Open Cyber University (OCU) in South Korea, which provides credit classes online for students who are enrolled at traditional brick-and-mortar universities. Twenty-three member universities make up the OCU, which offers 400 classes and serves 120,000 students per year (Open Cyber University of Korea, n.d.). In total, 2260 valid surveys were submitted, and after receiving the data file, responses from subjects who did not engage in any group work were excluded. This left 1455 subjects who were appropriate for participation in this study. Following this, linear regression of group work level and group work roles onto germane load was used to generate Mahalanobis, Cook's, and Leverage values in order to find outliers. Those participants whose results failed the standard for two or more of these tests were removed from the analysis, leaving 1399 eligible participants. No traits were shared when comparing the whole original set of surveys and the final 1399 eligible participants. The subsequent results and tables following this are derived from the 1399 remaining participants. Of 1399 remaining participants, 706 (50.5\%) were female and 693 (49.5\%) were male. The youngest subject was 18 , and the oldest subject was 52 , with a mean age of 23.63. The students who took part in this study took a variety of classes which filled a wide range of subject categories with the greatest number being liberal arts courses ( $31 \%$ of subjects), social science courses (17\%), information technology courses (15\%), lifestyle and health courses (14\%), management and business classes (7\%), foreign languages classes (7\%), natural sciences classes (5\%), and finally students taking design courses (4\%). The class distributions and break down of demographic variables is similar to previous research into cyber universities in South Korea in general (Suh \& Kim, 2013) and from research into the OCU specifically (Hughes et al., 2019).

\section{Instrument development}

To measure germane load, four items from Leppink et al. (2013) paper titled "The development of an instrument for measuring cognitive load" were adopted. This scale used Likert-type items ranging from 1 to 7 , with 1 being "strongly disagree" and 7 being "strongly agree". The four items measuring germane load used in the present study are as follows: (1) The lecture really enhanced my understanding of the topic, (2) the lecture really enhanced my knowledge and understanding of the of the class 
subject, (3) the lecture really enhanced my understanding of the concepts associated with the class subject, and (4) the lecture really enhanced my understanding of concepts and definitions. The four items were combined and averaged into a single construct labeled germane load. The Cronbach's alpha for the germane load variable was 0.956, which is appropriate for this type of research. In regards to germane cognitive load's validity and reliability, research by Klepsch and Seufert, (2020), showed that Leppink et al's (2013) cognitive load items are reasonably defined that germane load was a separated construct from the other aspects of cognitive load. Furthermore, even as a subjective judgement of learning, the conceptualization of germane load provides valuable insight into students' cognitive development (Leppink et al., 2015).

To measure the amount of group work, two variables were used: (1) group work variety and (2) group work regularity. In order to discover group work variety, participants were asked to respond to a single item which asked: How did you interact with people you know offline who were taking the same class? (Please check all that apply). The participants could respond by checking boxes with seven options: (1) we talked generally about the class ("The class is easy, the class is stressful"); (2) we talked about the contents of the class; (3) we studied together; (4) we shared notes or materials; (5) other (activities falling under this category included but were not limited to editing others work, checking answers, and reminders about dates/times/assessment); and (6) I never interacted with anyone offline. How the participants responded were then coded in six separate variables as either not occurring or occurring, with the five positive indicators (with the exclusion of I never interacted with anyone offline) being combined into a single additive index labeled group work variety. To generate the group work regularity variable, a single item was used. This read, Approximately, how much offline interaction did you have? The participants were then given five options to respond: (1) more than once a week (2) once a week, (3) once every 2 weeks, (4) once a month, and (5) I wasn't part of a study group. Students' responses on this item were combined with the group work variety index to create one total additive index called total group work, which was used as the independent variable for this study.

This research sought to gain a broad understanding of group work, so there was great variety in the way the students interacted. To investigate the amount of contribution students made to the group they were a part of, one item was used. This item asked participants to check a box stating what their main role was within the group. This created the data for the variable role in group work. The results from this item allowed the sorting of participants into three categories: high contributors, moderate contributors, and low contributors to group work. These were then put into categorical variables scored as 1 for low, 2 for moderate, and 3 for high. This variable was used as the moderating variable for this study. The subjects in this study were engaged in a variety of group work over the course of the semester. Each class would have had different group combinations and different types of activities. This includes group size and length of time working together. The variable is used to understand if being primarily a contributor of information or primarily a receiver of information is more beneficial. The Breusch-Pagan test and Koenker test were used to test for homoscedasticity. The variables used in this study met the assumptions of linear regression. 


\section{Common method variance}

An issue with research like that done in the present study relates to common method variance. This is because all items used in this study were taken from a single survey (Porumbescu, 2017). For this reason, the relationships discovered by that analysis of the variables the present study investigated may be subject to influences that may systematically affect relationships between variables, leading to erroneous relationships being discovered (Podsakoff et al., 2003). The key way to reduce common method bias in this type of research is in the design of the survey and the construction of the items (Jakobsen \& Jensen, 2015). There are several strategies suggested by MacKenzie and Podsakoff (2012) used in the present study to mitigate common method bias. These are that items should be simply worded, easy to understand and varied response scales. The scales used to measure germane cognitive load are easy-to-understand Likert type items that have been used in many previous studies without confusion. The measure of amount of group work asks students to simply check boxes of the type of group work they engaged in and how often, which should make it relatively clear and easy for them to complete. The role-taking variable also asks simply about their perceived level of contribution. While common method bias should still be considered, for the aforementioned reasons along with the lack of a strong relationship between role-taking and amount of group work, it is reasonable to believe the results of the present study are not greatly affected. For this reason, Harman single factor method for measuring common method bias was used. This analysis showed that a single factor accounted for $41 \%$ of the variance found regarding the variables of interest in the present study. This is below the cut-off of $50 \%$ and suggests that there is not systematic common method bias in the present study (Harman, 1976).

\section{Results}

The means, standard deviations, and Pearson correlation coefficients of the main variables used in this research are shown in Table 1. The results show that the amount of group work was negatively and significantly correlated with role in group work $(\beta=-0.097, p<0.05)$, though the correlation coefficient was small. Amount of group work was much more strongly and positively correlated with germane load $(\beta=0.551$, $p=<0.01)$. Finally, there was no statistically significant relationship between role in group work and germane load $(\beta=0.015, p=>0.05)$. The mean for the amount of group work was 4.37 , with a standard deviation of 1.71 . The mean for germane load was 4.88 , with a standard deviation of 1.24. Means and standard deviations were not calculated for role in group work as it was a categorical variable.

Table 1 Descriptive statistics and Pearson correlation coefficients of the main variables $(n=1399)$

\begin{tabular}{|c|c|c|c|c|c|}
\hline & Mean & SD & $\begin{array}{l}\text { Amount of group } \\
\text { work }\end{array}$ & $\begin{array}{l}\text { Role in group } \\
\text { work }\end{array}$ & Germane load \\
\hline Amount of group work & 4.37 & 1.71 & 1 & & \\
\hline Role in group work & N.A & N.A & $-0.097^{*}$ & 1 & \\
\hline Germane load & 4.88 & 1.24 & $0.551^{* *}$ & 0.015 & 1 \\
\hline
\end{tabular}

\footnotetext{
* Correlation is significant at the 0.05 level
}

** Correlation is significant at the 0.01 level 


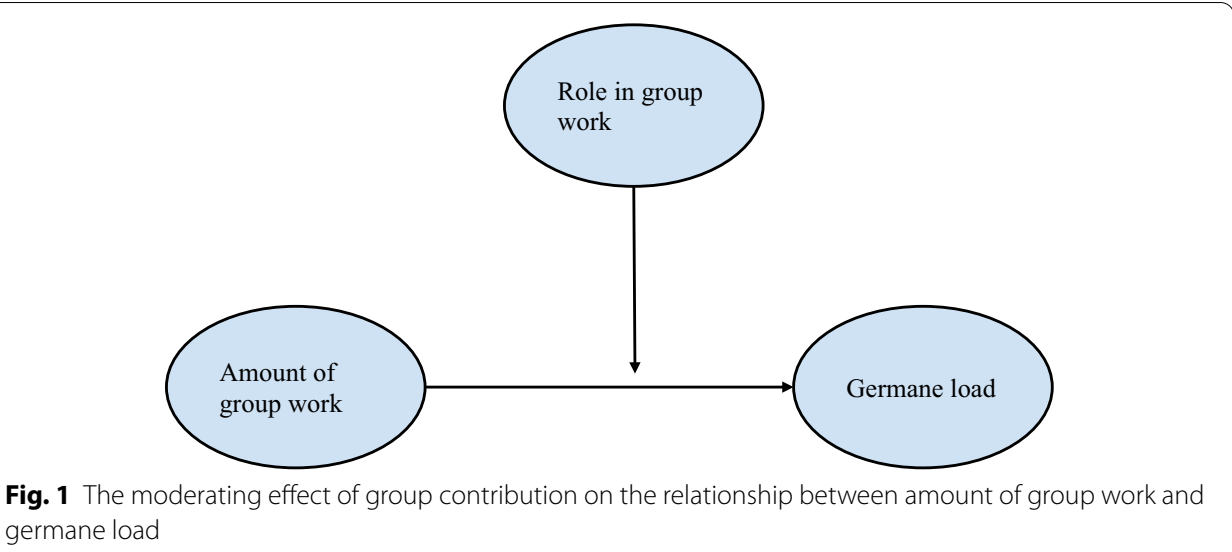

Table 2 Centered effects for amount of group work on germane load at each level of group role (contribution) $(n=1399)$

\begin{tabular}{lllllll}
\hline & Role & $b$ & $\mathrm{t}$ & $p$ & ULCI & LLCI \\
\hline Low contribution & -0.7243 & 0.5109 & 22.5791 & 0.000 & 0.9303 & 0.7052 \\
Moderate contribution & 0.00 & 0.4220 & 29.9078 & 0.000 & 0.6030 & 0.5008 \\
High contribution & 0.7243 & 0.3331 & 18.5358 & 0.000 & 0.3430 & 0.1208 \\
\hline
\end{tabular}

Linear regression was used to measure the effect of both role in group and amount of group work on germane load. Overall, the model predicted increased levels of germane load with moderate accuracy $\left(r^{2}=0.3224\right)$. This result shows that together both the independent variable and the moderating variable combined positively impacted germane cognitive load. More specifically, each unit increase in the amount of group work led to a $0.65(p=<0.001)$ increase in germane load.

To test the interaction effects of amount of group work and role in group work on germane load, PROCESS macro (model 1, Hayes, 2013) was used, as can be seen in Fig. 1. To show this, 10,000 bootstrap samples with a 95\% confidence interval were used. Furthermore, variables were mean centered to \pm 1 standard deviation, showing strong evidence of an interaction that was based on the standardized coefficients that were produced. Role in group work negatively moderated the relationship between amount of group work and germane load, or in other words, as a student's role changes to contribute more, the strength of the relationship between the amount of group work and germane load moderately decreases.

PROCESS macro was used to center variables and measure the moderated effect of amount of group work on germane load at the level of average role in group work, and at one standard deviation above and below the mean. Therefore, there were low, average, and high groupings of relationships between the amount of group work and germane load. In all three conditions, there was a statistically significant relationship between the amount of group work and germane load. However, as can be seen in Table 2, in the low contributor role condition, the effect size (0.51) is stronger than in the average contributor role condition, (0.42) and stronger again than in the high contributor role condition (0.33). As shown in Fig. 2, this creates an effect where the lines draw more closely 


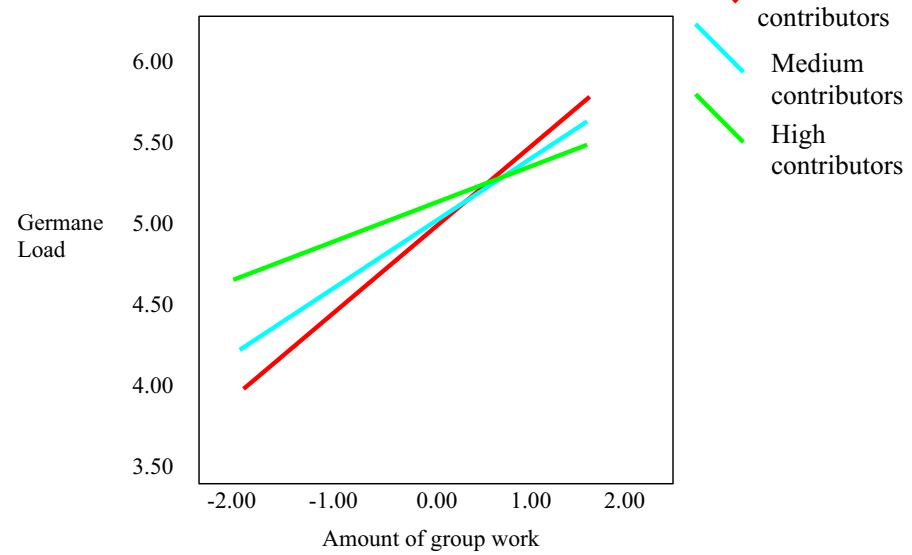

Fig. 2 The moderating effect of group contribution on the relationship between amount of group work and germane load

together, whereby the low contributor role condition has a steeper line than that of the average contributor role condition, and the high contributor role condition is slightly flatter than both. This leads to the lines intersecting where germane load and amount of group work is high.

\section{Discussion}

The present study shows that group work to support online classes will improve higherorder cognitive skills as represented by germane cognitive load. That is, as the amount of group work students engage in increases, so do learners' levels of cognitive germane load. This shows that the process of group collaboration leads to at least some level of perceived individual learning, which is the ultimate goal of much of online group work (Kalyuga, 2013). This may be caused by collaboration leading to greater effort put forth by learners, which may lead to greater learning. The present study gives support to the notion that collaborative learning can help with developing higher cognitive skills in online learning situations in which some learners struggle (Akyol \& Garrison, 2008; Kirschner et al., 2011). The present study goes some way to refuting claims that transaction cost in collaboration may harm learning by showing that greater variety and amount of learner-to-learner interaction lead to higher levels of cognitive development in the form of germane cognitive load. More specifically, the results found in the present study support research that shows that more interaction between learners leads to greater learning (Huang et al., 2019). Therefore, as this study shows, learners in groups that meet more often and engage in a greater variety of types of collaboration will benefit in the form of higher levels of germane cognitive load.

Some research claims that the scaffolding offered by the group to weaker members who make less of a contribution means that lower contributors benefit more (Pee et al., 2010). The present study showed that learners who make fewer contributions to group work have higher perceived levels of germane cognitive load than those who make a greater contribution to group work. Though the effect found in the present study is 
small, it is statistically significant. This result is likely caused by two factors. The first is the difficulty high contributors may have in subsuming their own goals and interests to the group's goals and interests (Järvelä et al., 2010). The second factor is the learnerto-learner interaction provided by the group offers low contributors the scaffolding and processing power of the high contributors in the group (Costley \& Lange, 2018; Pee et al., 2010). According to Duran (2017), those who teach contents to others will have a more complete understanding of those contents.

As each learner will contribute to their own level of knowledge and ability (Johnson \& Johnson, 2003), those who may be more knowledgeable will give the weaker members of the group the information they require. It may be that the higher contributors are tutoring the students who are making less of a contribution. This may lead to lower gains from group work for the high contributors and greater gains for the low contributors. This fits well within the current theoretical explanation of cognitive load in that the group work allows the sharing of mental models, which leads to greater cognitive development (Kirschner et al., 2018). According to Duran (2017), those who teach contents to others will have a more complete understanding of those contents. As each learner will contribute to their own level of knowledge and ability (Johnson \& Johnson, 2003), those who may be more knowledgeable will give the weaker members of the group the information they require. This helps explain the moderating effect that was found as part of the present study that provides a deeper understanding of the dynamics that are occuring the context of collaboration in online learning environments.

\section{Theoretical and practical implications}

The present study looked at how the amount of group work a learner does and his/her role within the group interact to affect germane load. More specifically, we asked if the members role in the group moderated the effect of more collaboration on germane cognitive load. The theoretical contribution of this paper is that we have shown that as the contribution to the group increased, the relationship between level of group work and germane cognitive load decreased. Although group work had a positive relationship with germane cognitive load, the relationship was weaker in the high contribution group work condition. In other words, doing more group work was more beneficial for the low contributors when compared with the high contributors. There is a kind of transaction here-high level contributors gain from teaching; low level contributors gain from scaffolding. Furthermore, in the present study, that transaction benefits the low contributor more than the high contributor. This research has shown that while group work benefits learners, learners do not have to be high contributors to gain these benefits. In fact, the learners who contribute less to the group achieve greater relative gains than those who contribute substantially to the group. This does not imply that being a high contributor to the group is bad per se, as the high contributors still benefited considerably from the group work; however, low contributors will make even greater gains.

This research helps to fill in our understanding of group work in online situations. The value of this to the field of educational research is that it gives a more well-rounded view of the nature of collaboration online and allows us to understand that the effects of collaboration are not just a factor of the amount of group work, but also related to the behaviors of the individuals within the group. Pedagogically speaking, this research 
adds to the body of literature by showing the value of varied types of learner-to-learner interactions within an online course that are happening regularly (the direct relationship between amount of group work and germane load). However, this research also shows that collaboration is of value for all learners, regardless of their contribution to group work. From a practical pedagogical point of view, this research allows us to see that learners are primarily gaining an advantage from just being a member of a group, not necessarily by making large contributions to that group. Based on this research, students should be encouraged to study together regardless of their level of knowledge or confidence. The main practical contribution of this study is to show that students who may not be able to contribute greatly to a group can still substantially benefit from the interactions they have with other learners.

\section{Conclusion and limitations}

In online learning environments, students will benefit when they are part of learning groups to help support their study towards their classes. One of the reasons this may be effective is that many large online courses lack student-to-student interaction, and these learning groups give students the opportunity to share what they know and what they have learned (Kirschner et al., 2009). The present study shows the importance of these groups by revealing the cognitive benefits students will get from studying together. Furthermore, this study shows that those learners who contribute little will also benefit from group work. The main limitation of this study is that it is based on a survey that deals with student perceptions of their levels of group work and germane load. Future research should utilize more varied constructs to create more focused and reliable measurements of the amount of group work learners are doing and their roles within the group. For example, controlled experiments where the learners' amount of group work are controlled and their contributions are observed and measured may allow a deeper understanding how different types of learners contribute to the group and how those contributions affect the group. Also, further investigation into the specific behaviors of those who classify themselves as high, moderate, or low contributors will allow us to more deeply understand how the specifics of group dynamics impact learning and collaboration. While the present model does show some effect of the collaborative variables on germane cognitive load, this model could be improved by the inclusion of other variables related to student interface with the learning environment usability. Furthermore, investigations into the issues of group formation and how group dynamics change over time will further develop our understanding of learner-to-learner interactions in an online setting. This research has value because it gives us a deeper understanding of the dynamics of learner-to-learner interaction as well as how those interactions impact learning. This area of research is fruitful for researchers as it helps give empirical weight to many of the assumptions of collaborative learning, and provides nuance to our understanding of theory.

Authors' contributions

The author read and approved the final manuscript.

Funding

There is no funding to declare in relation to this paper. 
Availability of data and materials

The data for this study was available to reviewers on reasonable request.

\section{Declarations}

\section{Ethics approval and consent to participate}

All procedures performed in studies involving human participants were in accordance with the ethical standards of the institutional and/or national research committee and with the 1964 Helsinki Declaration and its later amendments or comparable ethical standards.

\section{Competing interests}

The authors declare that they have no competing interests.

Received: 9 November 2020 Accepted: 25 March 2021

Published online: 30 April 2021

\section{References}

Akyol, Z., \& Garrison, D. R. (2008). The development of a community of inquiry over time in an online course: Understanding the progression and integration of social, cognitive and teaching presence. Journal of Asynchronous Learning Networks, 12(2-3), 3-23.

Andriessen, J., Baker, M., \& Suthers, D. (2003). Arguing to learn. Confronting Cognitions in computer-Supported collaborative learning environments. . Kluwer.

Chen, C. H., \& Yang, Y. C. (2019). Revisiting the effects of a project-based learning on students' academic achievement: A meta-analysis investigating moderators. Educational Research Review, 26(1), 71-81.

Cooke, N. J., Gorman, J. C., Duran, J. L., \& Taylor, A. R. (2007). Team cognition in experienced command-and-control teams. Journal of Experimental Psychology: Applied, 13, 146-157.

Costley, J., \& Lange, C. (2018). The moderating effects of group work on the relationship between motivation and cognitive load. The International Review of Research in Open and Distributed Learning, 19(1).

DeChurch, L. A., \& Mesmer-Magnus, J. R. (2010). The cognitive underpinnings of effective teamwork: A meta-analysis. Journal of Applied Psychology, 95(1), 32-53.

Duran, D. (2017). Learning-by-teaching. Evidence and implications as a pedagogical mechanism. Innovations in Education and Teaching International, 54(5), 476-484.

Harman, H. H. (1976). Modern factor analysis. . Chicago: University of Chicago Press.

Hayes, A. F. (2013). Introduction to mediation, moderation, and conditional process analysis. . The Guilford Press.

Hefter, M. H., \& Berthold, K. (2020). Preparing learners to self-explain video examples: Text or video introduction? Computers in Human Behavior, 110, 106404.

Hernández-Sellés, N., Muñoz-Carril, P. C., \& González-Sanmamed, M. (2019). Computer-supported collaborative learning: An analysis of the relationship between interaction, emotional support and online collaborative tools. Computers \& Education, 138, 1-12. https://doi.org/10.1016/j.compedu.2019.04.012.

Herrmann, K. J. (2013). The impact of cooperative learning on student engagement: Results from an intervention. Active Learning in Higher Education, 14(3), 175-187.

Homer, B. D., Plass, J. L., \& Blake, L. (2008). The effects of video on cognitive load and social presence in multimedia-learning. Computers in Human Behavior, 24(3), 786-797.

Huang, C. Q., Han, Z. M., Li, M. X., Jong, M. S. Y., \& Tsai, C. C. (2019). Investigating students' interaction patterns and dynamic learning sentiments in online discussions. Computers \& Education, 140, 103589.

Hughes, C., Costley, J., \& Lange, C. (2019). The effects of multimedia video lectures on extraneous load. Distance Education, $40(1), 54-75$.

Jakobsen, M., \& Jensen, R. (2015). Common method bias in public management studies. International Public Management Journal, 18(1), 3-30.

Järvelä, S., Volet, S., \& Järvenoja, H. (2010). Research on motivation in collaborative learning: Moving beyond the cognitive-situative divide and combining individual and social processes. Educational Psychologist, 45(1), 15-27.

Johnson, D. W., \& Johnson, R. T. (2003). Student motivation in cooperative groups. In R. M. Gillies \& A. F. Ashman (Eds.), Cooperative learning: The social and intellectual outcomes of learning in groups. (pp. 136-176). Oxfordshire: Routledge.

Johnson, D. W., Johnson, R. T., \& Smith, K. A. (2014). Cooperative learning: Improving university instruction by basing practice on validated theory. Journal on Excellence in University Teaching, 25(4), 1-26.

Kalyuga, S. (2013). Enhancing transfer by learning generalized domain knowledge structures. European Journal of Psychology of Education, 28(4), 1477-1493.

Kirschner, F., Paas, F., \& Kirschner, P. A. (2009). A cognitive load approach to collaborative learning: United brains for complex tasks. Educational Psychology Review, 21, 31-42

Kirschner, F., Paas, F., Kirschner, P. A., \& Janssen, J. (2011). Differential effects of problem-solving demands on individual and collaborative learning outcomes. Learning and Instruction, 21(4), 587-599.

Kirschner, P. A., Sweller, J., Kirschner, F., \& Zambrano, J. (2018). From cognitive load theory to collaborative cognitive load theory. International Journal of Computer-Supported Collaborative Learning, 3(2), 213-233. https://doi.org/10.1007/ s11412-018-9277-y.

Klepsch, M., \& Seufert, T. (2020). Understanding instructional design effects by differentiated measurement of intrinsic, extraneous, and germane cognitive load. Instructional Science, 48(1), 45-77.

Leppink, J., Paas, F., Van der Vleuten, C. P., Van Gog, T., \& Van Merriënboer, J. J. (2013). Development of an instrument for measuring different types of cognitive load. Behavior Research Methods, 45(4), 1058-1072. 
Leppink, J., van Gog, T., Paas, F., \& Sweller, J. (2015). Cognitive load theory: Researching and planning teaching to maximise learning. In Researching medical education (pp. 207-231)

MacKenzie, S. B., \& Podsakoff, P. M. (2012). Common method bias in marketing: Causes, mechanisms, and procedural remedies. Journal of Retailing, 88(4), 542-555.

Pee, L. G., Kankanhalli, A., \& Kim, H. W. (2010). Knowledge sharing in information systems development: A social interdependence perspective. Journal of the Association for Information Systems, $11(10), 550$.

Podsakoff, P. M., MacKenzie, S. B., Lee, J. Y., \& Podsakoff, N. P. (2003). Common method biases in behavioral research: A critical review of the literature and recommended remedies. Journal of Applied Psychology, 88(5), 879.

Porumbescu, G. (2017). Not all bad news after all? Exploring the relationship between citizens' use of online mass media for government information and trust in government. International Public Management Journal, 20(3), 409-441. https://doi.org/10.1080/10967494.2016.1269859.

Rienties, B., Tempelaar, D., Van den Bossche, P., Gijselaers, W., \& Segers, M. (2009). The role of academic motivation in Computer-Supported Collaborative Learning. Computers in Human Behavior, 25(6), 1195-1206.

Suh, S., \& Kim, S. (2013). Study on policy for an entrance quota of cyber universities. . Korea Educational Information and Research Service.

Swanson, E., McCulley, L. V., Osman, D. J., Scammacca Lewis, N., \& Solis, M. (2019). The effect of team-based learning on content knowledge: A meta-analysis. Active Learning in Higher Education, 20(1), 39-50.

Thom, M. (2020). Are group assignments effective pedagogy or a waste of time? A review of the literature and implications for practice. Teaching Public Administration, 38(3), 257-269.

Tsay, M., \& Brady, M. (2012). A case study of cooperative learning and communication pedagogy: Does working in teams make a difference? Journal of the Scholarship of Teaching and Learning, 10(2), 78-89.

Wosnitza, M., \& Volet, S. (2009). A framework for personal content goals in collaborative learning contexts. In Contemporary motivation research: From global to local perspectives (pp. 49-67).

Zhang, L., Kalyuga, S., Lee, C., \& Lei, C. (2016). Effectiveness of collaborative learning of computer programming under different learning group formations according to students' prior knowledge: A cognitive load perspective. Journal of Interactive Learning Research, 27(2), 171-192.

Zheng, L., Li, X., Zhang, X., \& Sun, W. (2019). The effects of group metacognitive scaffolding on group metacognitive behaviors, group performance, and cognitive load in computer-supported collaborative learning. The Internet and Higher Education, 42, 13-24.

\section{Publisher's Note}

Springer Nature remains neutral with regard to jurisdictional claims in published maps and institutional affiliations.

\section{Submit your manuscript to a SpringerOpen ${ }^{\circ}$ journal and benefit from:}

- Convenient online submission

- Rigorous peer review

- Open access: articles freely available online

- High visibility within the field

Retaining the copyright to your article

Submit your next manuscript at $\boldsymbol{\Delta}$ springeropen.com 